DOI: https://doi.org/10.24867/04BE29Markovic

\title{
AUTOMATSKO UPRAVLJANJE VIŠE SPREGNUTIH KLIMA KOMORA I BALANSIRANJE HVAC SISTEMA ČISTIH PROSTORA U NATPRITISKU
}

\section{AUTOMATIC CONTROL OF MULTIPLE AIR HANDLING UNITS SUPPLYING CLEAN AIR IN OVER PRESSURE AREAS}

\section{Jovan Marković, Fakultet tehničkih nauka, Novi Sad}

\section{Oblast - MAŠINSTVO - Merenje i Regulacija}

Kratak sadržaj - U ovom radu je prikazan elektromotorni pogon i BMS sistem čistih prostora objekata koji su u natpritisku za proizvodnju farmaceutskih proizvoda.

Ključne reči: elektromotorni pogon, BMS, čisti prostori, natpritisak

Abstract - This paper presents design project of the BMS system of clean areas in over-pressure for the production of pharmaceutical products.

Keywords: BMS (buliding management system), clean areas, over-pressure

\section{UVOD}

Fabrički kompleks „Fresenius Medical Care Srbija“ se nalazi u Tehnološkom parku u Vršcu i sastoji se iz više objekata: portirnice, glavnog objekta za proizvodnju medicinskih sredstava, energo bloka, skladišta opasnih materija, nadstrešnice za palete, nadstrešnice za kontejnere za sekundarne sirovine, kao i od podzemnih instalacija koje povezuju energanu i napojne vodove sa objektima.

Projekat EMP i automatike urađen je na osnovu projektnog zadatka, arhitektonsko-građevinskih podloga, tehnološkog projekta i projekta termotehničkih instalacija, koji sadrže podatke o opremi, nameni prostora, kao i zahtevane parametre koje treba ostvariti projektovanim sistemom. Projektom EMP i automatike se definiše kontrolni sistem (CS) koji upravlja procesom.

Projektnim zadatkom i tehnološkim projektom se ne zahteva praćenje stanja svih tehničkih sistema (hidrotehničkih instalacija, PP vode, sprinklera, statusa rada gasne kotlarnice i drugih pratećih sistema fabrike za proizvodnju medicinskih sredstava) preko kontrolnog sistema. Prate se samo statusi rada i kvara kotlarnice i sprinkler sistema.

Kontrolni sistem meri, reguliše i upravlja procesom. Sa stanovišta dobre proizvođačke prakse (GMP), kontrolni sistem treba da obezbedi sledeće:

Kontrolni sistem se mora realizovati kao zatvoren kontrolni sistem, tj. kao sistem sa kontrolisanim pristupom gde će se dodatno, u vidu elektronskog zapisa, beležiti i arhivirati svaka prijava, odjava i bezuspešan pokušaj prijave korisnika u sistem.

\section{NAPOMENA:}

Ovaj rad proistekao je iz master rada čiji mentor je bio prof. dr Zoran Mitrović.
- Komandovanje, vizuelizaciju procesa i implementaciju svih potrebnih regulacija

- Praćenje i arhiviranje svih GMP kritičnih procesnih veličina

- Detekciju alarmnih stanja i arhiviranje alarmnih poruka

- Obradu podataka.

Kontrolni sistem se sastoji iz 3 nivoa: NIVO OPREME U POLJU

Senzori i aktuatori, koji omogućavaju vezu nivoa automatizacije-upravljačkog sistema sa fizičkim parametrima procesa

NIVO AUTOMATIZACIJE (upravljački sistem)

PLC kontroleri koji omogućavaju:

- prihvat fizičkih merenja,

- regulaciju i vođenje procesa po unapred postavljenim parametrima

- vezu sa nadzornim nivoom

- praćenje parametara rada u toku samog delovanja sistema

- vođenje čitavog procesa bez komunikacijske veze sa nadzornim nivoom

\section{NIVO NADZORA I UPRAVLJANJA (CSNU)}

Prikaz, kontrola, arhiviranje, alarmiranje i protokoliranje za nadzirani objekat/objekte i samih veza između pojedinačnih nivoa

Uređaji u polju mogu pripadati grupi procesne instrumentacije (Process Instrumentation) ili pripadati grupi izvršnih elemenata-Aktuatora.

Uređaji iz grupe procesne instrumentacije (PI) pretvararaju fizičku veličinu u strujni signal. Strujni signali se kablovima zaštićenim od elektromagnetnih smetnji dovode na analogne i digitalne ulaze programabilno-logičkih kontrolera (PLC). PLC-ovi se nalaze u ormanima automatike i sa pratećom opremom prikupljaju signale iz polja i predaju naloge izvršnim elementima. Izvršni elementi služe da u skladu sa PLC programom izvršavaju aktivnosti propisane ovim projektom.

\section{MODOVI RADA KLIMA SISTEMA}

Klima sistemi su međusobno nezavisni. To znači da je moguće nezavisno svaki sistem uključiti, isključiti ili upravljati njime u ručnom modu.

Ručni mod klima sistema

Ovaj mod podrazumeva ručno upravljanje svakim izvršnim elementom ponaosob. Operater će sa HMI 
određivati položaj elementa i njihovo stanje. Ručni mod će služiti prilikom ispitivanja opreme ili nekih specifičnih radnji. Ne preporučuje se upotreba ručnog moda u normalnom radu.

\section{Automatski mod klima sistema}

Operater jednostavnim komandama START/STOP pokreće, odnosno zaustavlja sistem. Prilikom komande starta, program prolazi kroz nekoliko pripremnih faza, da bi na kraju ušao u fazu RAD. Ovaj mod se preporučuje za svakodnevni rad.

\section{Hibridni mod klima sistema}

Kada je sistem u automatskom radu, moguće je izabrani element prebaciti u ručni mod i njime upravljati po želji. Ovaj mod je pogodan za rad ako dođe do kvara na instrumentaciji, pa je potrebno ,premostiti“ automatsku regulaciju do neophodne poravke. Ne preporučuje se upotreba hibridnog moda u normalnom radu.

\section{Eko mod klima sistema}

Kada je sistem u automatskom radu, moguće ga je prebaciti u eko mod kada će sistem raditi sa smanjenim protokom, a uz održavanje kaskada pritisaka.

\section{REGULACIJA PROTOKA VAZDUHA PO SOBAMA}

Za regulacije protoka vazduha na ubacivanju u sobe se koriste CAV (constant air volume) elementi. Setpointi na CAV-ovima se postavljaju interno na samom uređaju, nezavisno od CS i oni nezavisno od CS održavaju konstantan protok, dok se CS-u šalje samo podatak o trenutnom protoku vazduha.

Za vrednosti internih setpointa treba konsultovati Tehnološki i Mašinski projekat.

Usled zahteva korisnika za održavanjem projektovanih pritisaka u ekonomskom režimu rada, na CAV-ovima će biti podešena 2 setpointa protoka. Vmax će biti setpoint protoka za normalan režim rada, a Vmin će biti setpoint redukovanog protoka, za ekonomski režim rada. Vrednost Vmax će biti u skladu sa projektovanim vrednostima, dok će se vrednost Vmin naknadno odrediti u dogovoru sa investitorom, a konsultujući Tehnološki i Mašinski projekat.

CS će određivati koji od ta dva setpointa će CAV-ovi održavati, tj. CS će određivati da li će CAV-ovi održavati Vmin ili Vmax.

CAV uređaji će održavati zadovoljavajući protok ako potisni ventilator zadovoljavajuće održava protok.

Korišćeni su CAV pokretači proizvođača Belimo, tip: LMV-D3-MP, slika 1.

\section{BELIMO}

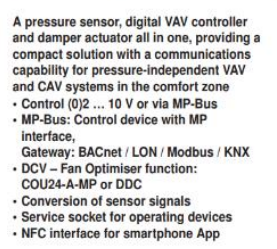

Slika 1. CAV regulator $L M V-D 3-M P$

\section{REGULACIJA PRITISKA PO SOBAMA}

Ova regulacija postoji u čistim sobama gde je potrebno održavati konstantan pritisak. Ova regulacija se ostvaruje elementom za regulaciju pritiska (VAV) i senzorom diferencijalnog pritiska u sobi. Setpoint se zadaje na CSNU i odgovara vrednostima koje su specificirane zahtevima iz Tehnološkog i Mašinskog projekta. Kao podrška radu VAV-ova se koristi ventilator izvlačenja.

U slučaju pojave kritičnog prevelikog ili premalog pritiska koji bi mogao da ugrozi plafon sobe, sistem odlazi u STOP.

NAPOMENA: U cilju bezbednog održavanja kaskade pritisaka između propusnika i prostorija, kontrolni sistem upravlja radom interlokova sa dvoje ili troje vrata.

Korišćen je VAV pokretač proizvođača Belimo, tip: NM 24A-SR, slika 2.
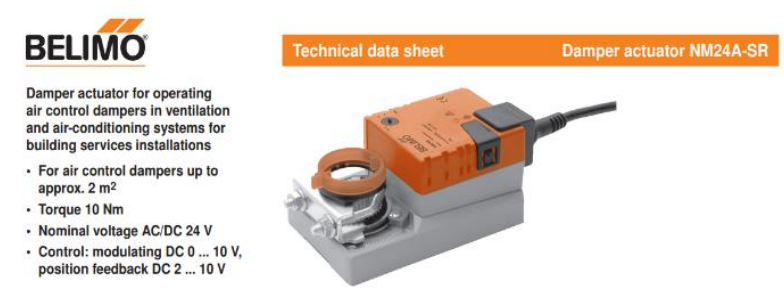

Slika 2. VAV regulator NM-24A-SR

Korišćen je senzor diferencijalnog pritiska proizvođača Siemens tip QBM 4100-1D, slika 3.

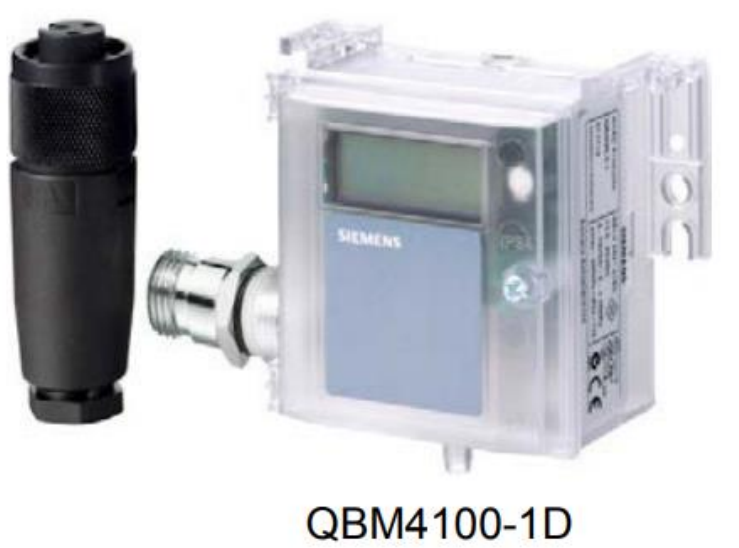

Slika 3. Siemens QBM 4100-1D

\section{OPIS RADA SISTEMA K8: AV SISTEMI}

Sistem K8 je predviđen za potrebe AV sistema. Namenjen je za vazdušno grejanje, hlađenje i ventilaciju. Sistem je sa $100 \%$ svežim vazduhom.

Ovaj sistem pokriva prostorije koje su klasificirane kao ISO 8. Jedan od kriterijuma je bio i minimalan broj izmena vazduha.

Klima komora K8_V1/K8_O1 se sastoji iz: usisne sekcije, prigušivača, glikolskog rekuperatora, ventilatora, mešne sekcije, filtera G4, toplovodnog grejača, hladnjaka, ventilatora i filtera F9. Sistem ima mogućnost da radi i sa recirkulacijom vazduha, te je zato predviđena mešna komora. U nominalnom režimu rada sistem radi sa $100 \%$ svežim vazduhom. Količina odsisnog vazduha je dimenzionisana na maksimalni kapacitet, ali se, ukoliko rade lokalni odnosi, količina odsisnog vazduha smanjuje. 
Sa ovim sistemom spregnuti su sistemi K8_O2, K8_O3, K8_O4, K8_O5, K8_O6.

Svi sistemi osim sistema K8_O5 su namenjeni za odsis sa AV linije. AV linija je tehnološki uređaj koji na 3 mesta ima priključke za otpadni vazduh. U kanalu iznad plafona čiste sobe predviđen je rekuperator toplote.

Sistem K8_O5 je predviđen za lokalne odsise sa stolova gde se vrši rad sa organskim rastvaračima. U kanalu iznad plafona čiste sobe predviđen je rekuperator toplote.

Glikolski rekuperatori u odsisnim sistemima su povezani $\mathrm{u}$ jedan sistem i dalje su povezani sa rekuperatorom $\mathrm{u}$ potisnoj sekciji. Predviđena je jedna zajednička centralna pumpa, dok je rekuperator u potisnoj sekciji sa trokrakim ventilom.

Za kancelariju je predviđen kanalski grejač koji dogreva vazduh i na taj način vrši lokalnu regulaciju temperature.

Održavanje pritiska se vrši pomoću regulatora protoka na izvlačenju. $\mathrm{Na}$ ubacivanju se nalaze regulatori protoka koji obezbeđuju konstantnu količinu vazduha na ubacivanju.

Ubacivanje vazduha se vrši kroz difuzore sa ugrađenim HEPA filterima.

\section{APLIKATIVNA ŠEMA JEDNOG OD SISTEMA VENTILACIJE ČISTOG PROSTORA U NATPRI- STISKU K-8}

Aplikativna šema detaljno prikazuje spisak signala koji se preuzima sa periferne opreme u polju, kao i tip signala. (analogni ili digitalni). Signali se obrađuju u PLC-u (Siemens S7-400) i na osnovu predefinisanih programa vrši se delovanje na izvršne elemente, u ovom slučaju CAV i VAV regulatore čijim upravljanjem se i obezbeđuju projektovani parametri u prostoru. U nastavku je prikazana aplikativna šema klima komore K-08.

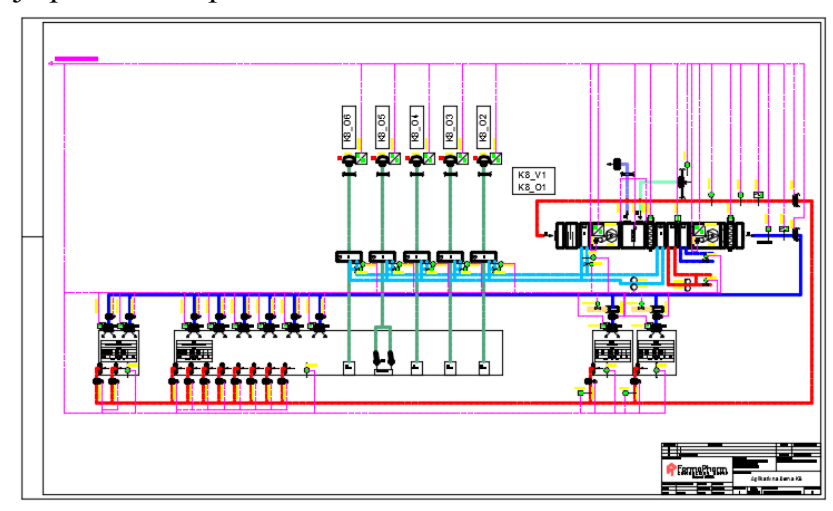

Šema 1.Aplikativna šema klima komore $K-08$

\section{SKADA PRIKAZ SISTEMA K8}

Zbog vrlo pozitivnog iskustva, jako velikih mogućnosti, visoke pouzdanosti i fleksibilnosti, projektom je predviđeno da se kao bazni programski paket za realizaciju CSNU koristi Vijeo Citect sa svim svojim komponentama.

Redundantni SCADA serveri su predviđeni zbog sigurnosti, s obzirom da su svih 12 PLC-ova povezani sa jednim serverom. U normalnom radu u funkiciji je primarni (Primary) server dok je sekundarni (Stand By) u ,stand by“ modu. U slučaju nekog problema sa računarom primarnog servera ili sa njegovom komunikacijom sa PLCovima, sekundarni server automatski prelazi u funkciju dok se primarni ponovo ne osposobi. Samo serveri obavljaju komunikaciju sa PLC-ovima i na njima se realizuju sve funkcionalnosti SCADA sistema. Svaki server se sastoji od IO servera, Alarm Servera, Trend servera i Report servera.

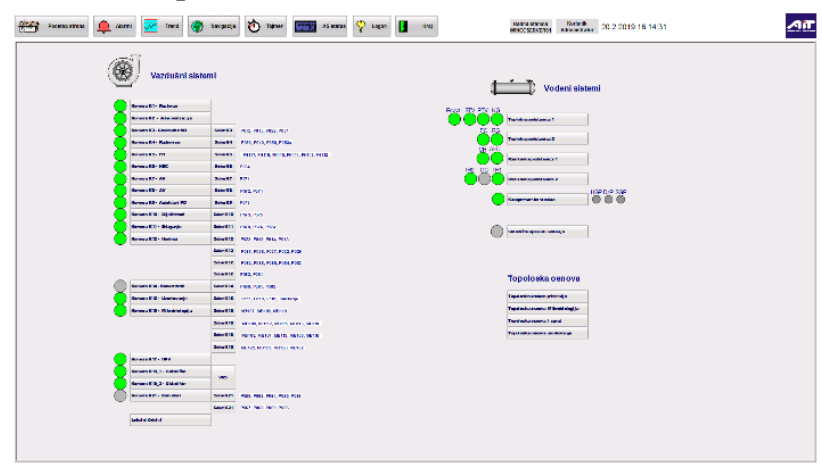

Slika 4. skada, početni ekran sa klima komorama

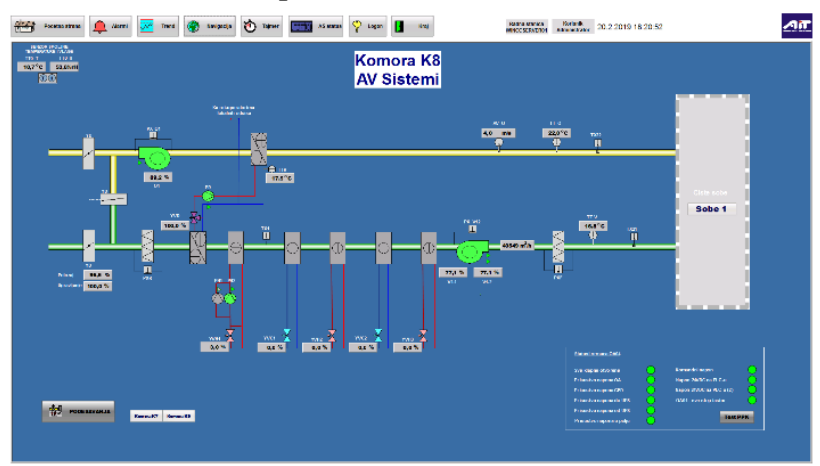

Slika 5. skada, početni ekran sa klima komorom $K-8$

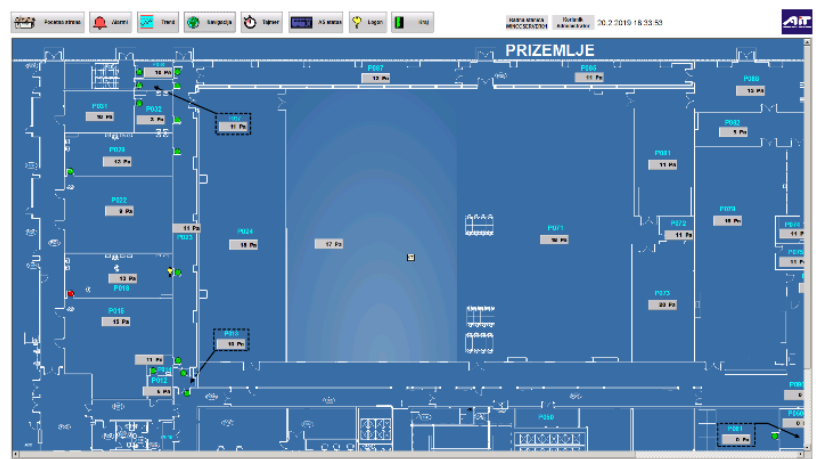

Slika 6. skada, osnova sa prikazom ostvarenih pritisaka

\section{ZAKLJUČAK}

U radu su prikazani osnovni delovi elektromotornog pogona i BMS-a (building menagement system) primenjeni u fabričkom kompleksu „Fresenius Medical Care Srbija“" u Vršcu, koji je po svojoj prirodi, s obzirom na to da je u pitanju proizvodnja lekova i koncentrata, na najvišem mogućem nivou. Prikazan je princip merenja realnih parametara u polju, putem najpreciznije periferne senzorike i ostvarivanje zadatih parametara delovanjem na izvršne elemente u polju.

Pošto su u pitanju osetljivi i precizni signali, poseban akcenat je stavljen na instalaterski deo, gde je prikazana tačna definicija signalnih kablova položenih za međuvezu ormana elektromotornog pogona periferne opreme, kako bi se eliminisala mogućnost smetnji i slabljenja signala kroz samu položenu instalaciju. 
Kako je zaustavljanje rada ventilacije i zatvaranje PP klapni (protivpožarnih klapni) na granicama požarnih sektora preduslov za primanje objekta od strane PP inspekcije, ekspliciitno su navedeni položaji, instalacije i tipovi ugrađenih PP klapni.

Korisnički deo, vizualizacija BMS sistema, tj. skada softver je prikazan kroz nekoliko slika realno izvedenog i u potpunosti funkcionalnog sistema koji je u eksploataciji više od tri godine.

\section{Kratka biografija:}

Jovan Marković rođen je u Somboru 1985. god. Master studije mehatronike završio je 2013. god. Tokom školske 2018/2019. upisao se na master studije na studijskom programu Merenje i regulacija na Fakultetu tehničkih nauka u Novom Sadu.

kontakt: jovanmax@gmail.com 